Criado, A., Conde, A. \& MÁrquez, R. (1983). Acta Cryst. C39, $122-125$.

Criado, A., Conde, A. \& Márquez, R. (1984). Acta Cryst. C40, $188-190$.

Galbis Pérez, J. A., Avalos González, M., Jiménez Requejo, J. L. \& Palacios Albarrán, J. C. (1983). Carbohydr. Res. 124, C15-C 17.

Hamilton, W. C. (1959). Acta Cryst. 12,609-610.

International Tables for X-ray Crystallography (1974). Vol. IV. Birmingham: Kynoch Press. (Present distributor D. Reidel, Dordrecht.)

Longchambon, F., Ohanessian, J., Avenel, D. \& Newman, A. (1975). Acta Cryst. B31, 2623-2627.

Longchambon, F., Ohanessian, J. \& Gillier-Pandraud, $\mathrm{H}$. (1981). Acta Cryst. B37, 601-607.
Main, P., Fiske, S. J., Hull, S. E., Lessinger, L., Germain, P., DeClercQ, J.-P. \& Woolfson, M. M. (1980). MULTAN80. A System of Computer Programs for the Automatic Solution of Crystal Structures from X-ray Diffraction Data. Univs. of York, England, and Louvain, Belgium.

NARDELLI, M. (1983). Acta Cryst. C39, 1141-1142.

Ohanessian, J., Longchambon, F. \& Arene, C. (1978). Acta Cryst. B34, 3666-3671.

Shimizu, N., Nishigaki, S., NaKaI, Y. \& Osakı, K. (1982). Acta Cryst. B38, 2309-2311.

Stewart, J. M., Kundell, F. A. \& Baldwin, J. C. (1970). The $X R A Y 70$ system. Computer Science Center, Univ. of Maryland, College Park, Maryland.

Taylor, R. \& Kennard, O. (1982). J. Am. Chem. Soc. 104, 5063-5070.

\title{
Structure and Absolute Configuration of $1^{\prime}$-(p-Bromophenyl)-3' -ethyl-1', $\mathbf{1}^{\prime}, \mathbf{4}^{\prime}, 5^{\prime}$ - tetrahydro-1,2-dideoxy- $\alpha$-L-glucofuranoso[2,1-d]imidazole-2' -thione Monohydrate,* $\mathrm{C}_{15} \mathrm{H}_{19} \mathrm{BrN}_{2} \mathrm{O}_{4} \mathrm{~S}_{2} \mathrm{H}_{2} \mathrm{O}$
}

\author{
By C. F. Conde, M. Millan, A. Conde and R. Márquez \\ Departamento de Optica y Sección de Física del Centro Coordinado del CSIC, Universidad de Sevilla, Spain
}

(Received 27 June 1984; accepted 15 October 1984)

\begin{abstract}
M_{r}=421 \cdot 30$, monoclinic, $P 2_{1}, a=7.531$ (1), $b=8.148$ (4), $c=14.625$ (2) $\AA, \beta=97.14(1)^{\circ}, V=$ $890.5(5) \AA^{3}, \quad Z=2, \quad D_{m}=1.58(1), \quad D_{x}=$ $1.571 \mathrm{Mg} \mathrm{m}^{-3}$, Mo $K \alpha, \lambda=0.7107 \AA, \mu=2.42 \mathrm{~mm}^{-1}$, $F(000)=432, T=300 \mathrm{~K}, R=0.065$ for 1672 observed independent reflexions. The sugar ring adopts a ${ }^{4} T_{3}$ conformation and the dihedral angle in the bicyclic system is $72.3(4)^{\circ}$. A three-dimensional network of hydrogen bonds links the molecules to build up the crystal structure.
\end{abstract}

Introduction. The structure determination of the title compound (I) was undertaken as part of a continuing research project in this laboratory involving glucimidazoles and imidazole $C$-nucleosides. During the past few years amino-sugars have been used in the preparation of these compounds (Garcia González, Fernández-Bolaños \& Lopez-Aparicio, 1976; Fernández-Bolaños, Galbis Pérez \& Zamora Mata, 1984; Galbis Pérez, Palacios Albarrán, Jiménez Requejo \& Avalos González, 1984) via 1-arylglucofuranosoimidazolidine-2-thiones. Some of these compounds, prepared in the Organic Chemistry Department of the University of Extremadura, have

* IUPAC name: 6-(p-bromophenyl)-2-(1,2-dihydroxyethyl)-4ethyl-3-hydroxy-2,3,3a,5,6,6a-hexahydrofuro $2,3-d \mid$ imidazole$5(4 H)$-thione monohydrate.

0108-2701/85/020277-04\$01.50 been studied in order to establish the conformational details of the molecule in the solid state (for example, Estrada, Conde \& Márquez, 1983, 1984). Galbis Pérez et al. (1984) have reported the application of aminonitrile synthesis to the preparation of the new 2-deoxy-2-(ethylamino)- $\alpha$-L-glucopyranose hydrochloride and its reaction with 4-bromophenyl isothiocyanate, to afford the title compound. Its chemical nature was established from elemental analysis and spectroscopic IR and NMR data and the X-ray analysis was carried out to define the structural details.

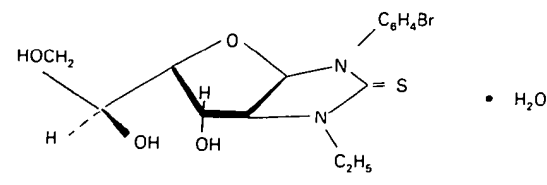

(I)

Experimental. Single crystals in the form of colourless needles elongated along [100] prepared in the Organic Chemistry Department of the University of $\mathrm{Ex}^{-}$ tremadura and kindly supplied by Professor J. A. Galbis. $D_{m}$ by flotation method. Crystal $0.09 \times 0.14 \times$ $0.30 \mathrm{~mm}$. Unit-cell parameters by least squares from 25 reflexions, $5<\theta<18^{\circ}$. Enraf-Nonius CAD-4 diffractometer, graphite monochromator, $2 \theta<60^{\circ}$ $(-10 \leq h \leq 10,0 \leq k \leq 11,0 \leq l \leq 20), \omega-2 \theta$ scan

(c) 1985 International Union of Crystallography 
mode. Two standard reflexions $(103,004)$ : variation in intensity less than $2.5 \%$ of the mean value. 2745 independent reflexions measured, 1073 considered unobserved $[I<2 \sigma(I)]$. Lorentz and polarization correction; no correction for absorption $(\mu R \sim 0.15)$ or extinction. Patterson function and heavy-atom method with the initial set of phases based on $\mathrm{Br}$-atom position. Full-matrix least-squares refinement on $F$, anisotropic; difference Fourier synthesis revealed the $21 \mathrm{H}$-atom positions; isotropic temperature factor for each $\mathrm{H}$ atom equal to that of the atom bonded to it; further least-squares refinement including the positional parameters of the $\mathrm{H}$ atoms and anomalous-dispersion corrections for $\mathrm{Br}$ and $\mathrm{S}$ atomic scattering factors (International Tables for $X$-ray Crystallography, 1974) reduced $R_{w}$ to $0.071(R=0.065)$; weighting scheme based on a statistical count criterion $\left(w=1 / \sigma^{2}\right)$. $(\Delta / \sigma)_{\max }=0.04 . S=2.05$ for 217 refined parameters. Final difference synthesis showed $0.40>\Delta \rho>$ $-0.30 \mathrm{e} \AA^{-3}$.

The enantiomorphic form of the molecule was refined separately and converged to a final $R_{w}$ value of 0.076 $(R=0.071)$. The application of the $\mathscr{R}$ test (Hamilton, $1965)$ indicates that the first enantiomorph is correct at a significance level much lower than $0.005\left[R_{w}(2) /\right.$ $\left.R_{w}(1)=1.092 ; \mathscr{R}_{1,1455,0.005} \simeq 1.003\right]$ and, therefore, can be retained as the absolute configuration. Moreover, this absolute configuration is consistent with that defined by reference to the sugar moiety. Crystallographic programs of the XRAY70 system (Stewart, Kundell \& Baldwin, 1970) were used throughout.

Discussion. Fractional atomic coordinates and equivalent isotropic temperature factors (Hamilton, 1959) for non-hydrogen atoms are given in Table 1.* Bond lengths and angles involving non-hydrogen atoms are listed in Fig. 1.

Bond distances and angles in the imidazolidine ring agree with the mean values reported for analogous glucofuranoimidazolidine-2-thione compounds (Conde, Bernier \& Márquez, 1980; Estrada, Conde \& Márquez, 1983, 1984).

The observed asymmetry for the $\mathrm{N}(1)-\mathrm{C}(1)$ and $\mathrm{N}(2)-\mathrm{C}(1)$ lengths $(\Delta / \sigma=3.51)$ indicates the influence of the substituents at $N(1)$ and $N(2)$ on the resonance:

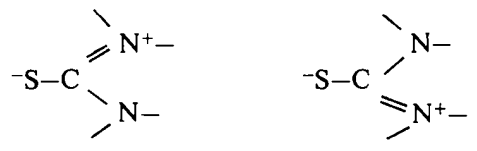

\footnotetext{
* Lists of structure factors, anisotropic thermal parameters and $\mathrm{H}$-atom parameters have been deposited with the British Library Lending Division as Supplementary Publication No. SUP 39834 (14 pp.). Copies may be obtained through The Executive Secretary, International Union of Crystallography, 5 Abbey Square, Chester CH1 2HU, England.
}

The imidazolidine ring is not planar; the ring atoms deviate significantly $\left[\Sigma(\Delta / \sigma)^{2}=156 \cdot 5\right]$ from the leastsquares plane Ithe value of the total puckering amplitude (Cremer \& Pople, 1975) is $Q=$ $0.122(10) \AA]$ and this feature, not found for monosubstituted [only at $\mathrm{N}(1)$ ] glucofuranoimidazolidine compounds, has been observed also in a recently reported analogous structure (Estrada, Conde \& Márquez, 1983).

Table 1. Atomic fractional coordinates $\left(\times 10^{4}\right)$ and equivalent isotropic temperature factors $\left(\AA^{2} \times 10^{3}\right)$

\begin{tabular}{lcccc}
\multicolumn{5}{c}{$U_{\text {eq }}=\frac{1}{3} \sum_{i} \sum_{j} U_{i j} a_{i}^{*} a_{j}^{*} a_{i} a_{j} \cos \left(\mathbf{a}_{i} \cdot \mathbf{a}_{j}\right)$} \\
$\mathrm{Br}$ & $x$ & $y$ & $z$ & $U_{\mathrm{eq}}$ \\
$\mathrm{Br}$ & $9014(2)$ & 10000 & $-21(1)$ & $607(5)$ \\
$\mathrm{S}$ & $5891(4)$ & $3728(5)$ & $2514(2)$ & $389(9)$ \\
$\mathrm{C}(1)$ & $3943(12)$ & $4787(15)$ & $2400(7)$ & $260(29)$ \\
$\mathrm{C}(2)$ & $2069(14)$ & $7112(15)$ & $2276(7)$ & $308(34)$ \\
$\mathrm{C}(3)$ & $1012(13)$ & $5565(12)$ & $2538(7)$ & $235(27)$ \\
$\mathrm{C}(4)$ & $366(12)$ & $6051(15)$ & $3449(7)$ & $294(32)$ \\
$\mathrm{C}(5)$ & $1849(13)$ & $7221(15)$ & $3835(6)$ & $261(30)$ \\
$\mathrm{C}(6)$ & $1455(13)$ & $8395(15)$ & $4592(6)$ & $292(33)$ \\
$\mathrm{C}(7)$ & $3007(14)$ & $9499(15)$ & $4901(8)$ & $345(37)$ \\
$\mathrm{C}(8)$ & $4983(13)$ & $7236(12)$ & $1589(6)$ & $208(27)$ \\
$\mathrm{C}(9)$ & $5718(15)$ & $6453(16)$ & $884(8)$ & $372(37)$ \\
$\mathrm{C}(10)$ & $6911(15)$ & $7311(18)$ & $406(8)$ & $420(41)$ \\
$\mathrm{C}(11)$ & $7359(15)$ & $8912(15)$ & $636(8)$ & $337(35)$ \\
$\mathrm{C}(12)$ & $6594(16)$ & $9698(16)$ & $1313(8)$ & $396(39)$ \\
$\mathrm{C}(13)$ & $5425(16)$ & $8869(17)$ & $1809(8)$ & $378(38)$ \\
$\mathrm{C}(14)$ & $2042(16)$ & $2651(15)$ & $2994(9)$ & $353(39)$ \\
$\mathrm{C}(15)$ & $585(22)$ & $1816(17)$ & $2390(14)$ & $789(69)$ \\
$\mathrm{O}(1)$ & $2274(10)$ & $8127(10)$ & $3054(5)$ & $308(25)$ \\
$\mathrm{O}(2)$ & $-1270(9)$ & $6957(10)$ & $3255(6)$ & $367(26)$ \\
$\mathrm{O}(3)$ & $895(11)$ & $7503(12)$ & $5327(5)$ & $413(28)$ \\
$\mathrm{O}(4)$ & $4545(9)$ & $8597(13)$ & $5279(5)$ & $417(27)$ \\
$\mathrm{O}(5)$ & $2948(11)$ & $4691(12)$ & $5852(7)$ & $574(36)$ \\
$\mathrm{N}(1)$ & $3781(12)$ & $6407(12)$ & $2089(6)$ & $309(29)$ \\
$\mathrm{N}(2)$ & $2399(12)$ & $4279(12)$ & $2644(6)$ & $292(28)$
\end{tabular}

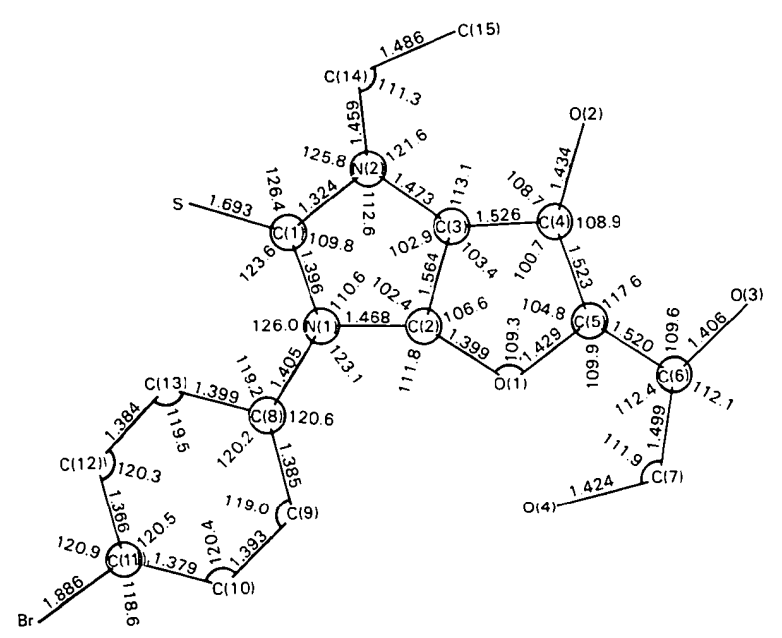

Fig. 1. Bond lengths $(\AA)$ and angles $\left({ }^{\circ}\right)$ in the molecule. (Standard deviations are in the ranges $0.010-0.020 \AA$ and $0.7-1.1^{\circ}$, respectively.) 
Bond lengths and angles in the furanosyl ring are close to the mean values observed for analogous compounds. The typical asymmetry of the endocyclic bonds $\mathrm{O}(1)-\mathrm{C}(2)$ and $\mathrm{O}(1)-\mathrm{C}(5)$ in these compounds due to anomeric effects seems to be present; however, the feature is difficult to establish in this case because of the high e.s.d.'s $(\Delta / \sigma=1.58)$. The glucofuranose ring is not planar as expected. In terms of the ring-puckering coordinates (Cremer \& Pople, 1975) the amplitude and phase magnitudes are 0.373 (11) $\AA$ and $125.5(15)^{\circ}$ for the sequence $O(1)-C(2)-C(3)-C(4)-C(5)$ and the resulting conformation corresponds to a puckering mode $\left({ }^{4} T_{3}\right)$ similar to that found in a recently reported analogous compound (Estrada, Conde \& Márquez, $1983)$. The asymmetry parameter of Nardelli $(1983 a)$ is $\Delta C_{2}[C(2)]=0.0052(46)$. The small value of the torsion angle $\mathrm{O}(1)-\mathrm{C}(2)-\mathrm{C}(3)-\mathrm{C}(4)=11.4(10)^{\circ}$ is another feature of these compounds and may be attributed to distortion of the furanosyl ring due to the ring fusion.

The two rings show a cis form of junction, as is found in analogous compounds, with the bonds at $\mathrm{C}(2)$ and C(3) nearly eclipsed. The dihedral angle between the least-squares planes through the imidazolidine and furanosyl rings is $72.9(4)^{\circ}$.

The phenyl ring, planar as expected $\left[\Sigma(\Delta / \sigma)^{2}=3 \cdot 8\right.$; $\chi^{2}=7.8$ at $95 \%$, forms a dihedral angle of $47.2(4)^{\circ}$ with the imidazolidine ring. Values of this dihedral angle in the range $45-80^{\circ}$ were found in analogous compounds, except for the value of $15 \cdot 1(6)^{\circ}$ in the case of $1^{\prime}$-phenyl-1', $3^{\prime}, 4^{\prime}, 5^{\prime}$-tetrahydro-1,2-dideoxyglucofuranoso[ 1,2-d]imidazol-2-one (Conde, Bernier \& Márquez, 1980).

The ethyl group is also twisted with respect to the imidazolidine ring as indicated by the torsion angle $\mathrm{C}(1)-\mathrm{N}(2)-\mathrm{C}(14)-\mathrm{C}(15)=-120 \cdot 1(13)^{\circ}$.

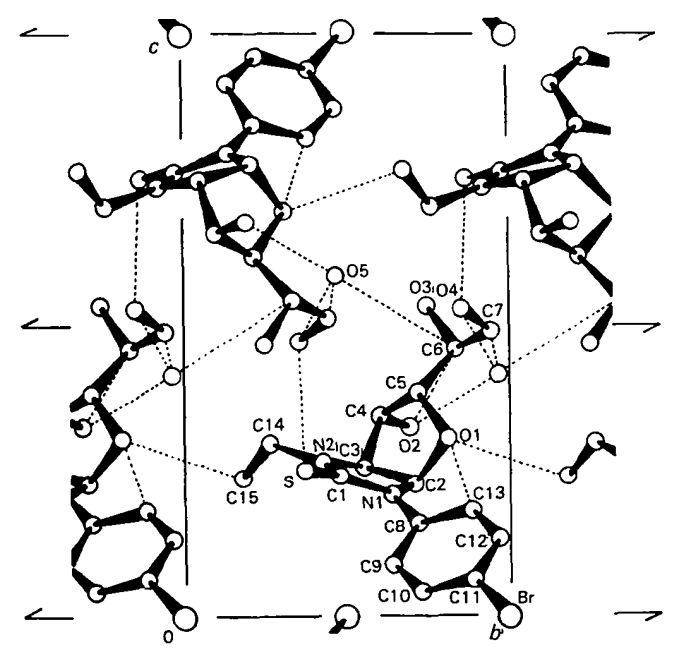

Fig. 2. A view along $[100 \mid$ of the unit-cell contents. Hydrogen bonds are indicated by dashed lines.
Table 2. Geometry of the possible hydrogen bonds

\begin{tabular}{|c|c|c|c|c|}
\hline$X-\mathrm{H} \cdots Y$ & $X \cdots Y(\AA)$ & $X-\mathrm{H}(\AA)$ & $\mathrm{H} \cdots Y(\AA)$ & $X-\mathrm{H} \cdots Y\left(^{\circ}\right)$ \\
\hline$-H(13) \cdots O(1)$ & $3.223(15)$ & $0.94(15)$ & $2.53(15)$ & $130(11)$ \\
\hline $\mathrm{C}(6$ & $2 \cdot 900(12)$ & $0.80(13)$ & $2 \cdot 39$ & $122(14)$ \\
\hline (Ii) & 3.359 & 1.040 & & $136(14)$ \\
\hline $\mathrm{C}(6)-\mathrm{H}(6) \cdots \mathrm{O}\left(5^{\mathrm{ii}}\right)$ & $3.463(13)$ & $0.80(13)$ & $2.78(14)$ & $144(12)$ \\
\hline $\mathrm{C}(7)-\mathrm{H}(71) \cdots \mathrm{O}\left(5^{\text {(ii) }}\right)$ & 3.369 (14) & $0.85(15)$ & $2 \cdot 80(15)$ & $126(13)$ \\
\hline$H(O 51) \cdots O\left(2^{i v}\right)$ & 2.945 (13) & $1.08(19)$ & $2 \cdot 10(18)$ & $134(14)$ \\
\hline $\mathrm{O}(5$ & $2 \cdot 806(13)$ & $1.06(18)$ & $1.89(18)$ & $143(14)$ \\
\hline $\mathrm{O}(4)-\mathrm{H}(\mathrm{O} 4) \cdots \mathrm{S}$ & $3.287(9)$ & $0.87(15)$ & $2.47(15)$ & 156 (13) \\
\hline
\end{tabular}

Symmetry code: none $x, y, z$; (i) $x, y-1, z$; (ii) $-x, y+\frac{1}{2},-z+1$; (iii) $-x+1, y+\frac{1}{2},-z+1$; (iv) $-x, y-\frac{1}{2},-z+1$; (v) $-x+1, y-\frac{1}{2}$, $-z+1$.

\section{Crystal packing}

Fig. 2 shows the contents of the unit cell viewed down [100]. The crystal structure is stabilized by a three-dimensional hydrogen-bonding network; there are also two intramolecular interactions $[\mathrm{C}(13)-\mathrm{H}(13) \ldots$ $\mathrm{O}(1)$ and $\mathrm{C}(6)-\mathrm{H}(6) \cdots \mathrm{O}(2)]$ that could also be hydrogen bonds (Jeffrey \& Maluszynska, 1982; Berkovitch-Yellin \& Leiserowitz, 1984). Molecules are linked to form chains parallel to [010] by $\mathrm{C}(15)-\mathrm{H}(153) \cdots \mathrm{O}(1)(x, y-1, z)$ hydrogen bonds. On the other hand molecules are linked along [100], through the hydration water molecule, by two hydrogen bonds: $\mathrm{O}(5)-\mathrm{H}(\mathrm{O} 51) \cdots \mathrm{O}(2)\left(-x, y-\frac{1}{2},-z+1\right)$ and $\mathrm{O}(5)-\mathrm{H}(\mathrm{O} 52) \cdots \mathrm{O}(4)\left(-x+1, y-\frac{1}{2},-z+1\right)$. Finally, each molecule is linked to the neighbour related by a twofold screw axis by $\mathrm{O}(4)-\mathrm{H}(\mathrm{O} 4) \cdots \mathrm{S}\left(-x+1, y+\frac{1}{2}\right.$, $-z+1)$. Details of the geometry of these hydrogen bonds are given in Table 2 .

For the two $\mathrm{O}-\mathrm{H} \cdots \mathrm{O}$ contacts listed in Table 2 involving the hydration water molecule, the values of the $d$ parameter, defined as the difference between the sum of the van der Waals radii and the interatomic distance (Taylor \& Kennard, 1982), are 0.60 and $0.81 \AA$ respectively, both satisfying the rule $d>0.3 \AA$. For the short $\mathrm{C}-\mathrm{H} \cdots \mathrm{O}$ interactions only the intramolecular contact $\mathrm{C}(6)-\mathrm{H}(6) \ldots \mathrm{O}(2)$ has a value $d \simeq 0.3$ and the angles $\mathrm{C}-\mathrm{H} \cdots \mathrm{O}$ are, in all cases, far from the ideal linear configuration. However, a high dispersion in experimental values of $\mathrm{C}-\mathrm{H} \ldots \mathrm{O}$ angle is found for interactions with $d>0.3$ (Taylor \& Kennard, 1982). Finally, the existence of short O-H $\cdots \mathrm{S}$ contacts has been found in other imidazolidine-2-thione compounds and, perhaps, it could be associated with the negative charge at $S$ in the resonance forms of the thiourea system. No other intermolecular contact significantly shorter than the sum of the van der Waals radii has been detected. The molecular geometry and crystal packing were computed by PARST (Nardelli, 1983b).

The authors thank Professor J. Galbis for supplying the crystals and for helpful discussions on chemical aspects and Professor A. López-Castro for collecting the diffractometric data. The present work is part of a research project supported by a grant from the CAICYT of the Government. 


\section{References}

Berkovitch-Yellin, C. \& Leiserowitz, L. (1984). Acta Cryst. B40, 159-165.

Conde, A., Bernier, F. \& Márquez, R. (1980). Acta Cryst. B36, 3048-3052.

Cremer, D. \& Pople, J. A. (1975). J. Am. Chem. Soc. 97, 1354-1358.

Estrada, M. D., Conde, A. \& Márquez, R. (1983). Acta Cryst. C39, 1418-1421.

Estrada, M. D., Conde, A. \& Márquez, R. (1984). Acta Cryst. C40, 898-901.

Fernández Bolaños, J., Galbis Pérez, J. A. \& Zamora Mata, F. (1984). An. Quim. 80C. In the press.

Galbis Pérez, J. A., Palacios Albarrán, J. C., Jiménez Requejo, J. L. \& Avalos GonzÁlez, M. (1984). Carbohydr. Res. 129. In the press.
Garcia González, F., Fernández Bolaños, J. \& Lopez Aparicio, F. J. (1976). Am. Chem. Soc. Symp. Ser. 39, 207-226.

Hamilton, W. C. (1959). Acta Cryst. 12, 609-610.

Hamilton, W. C. (1965). Acta Cryst. 18, 502-510.

International Tables for X-ray Crystallography (1974). Vol. IV. Birmingham: Kynoch Press.

JefFrey, G. A. \& MALuSzynSka, H. (1982). Int. J. Biol. Macromol. 4, 173-185.

NARDELli, M. (1983a). Acta Cryst. C39, 1141-1142.

NARDELli, M. (1983b). Comput. Chem. 7, 95-98.

Stewart, J. M., Kundell, F. A. \& Baldwin, J. C. (1970). The $X R A Y 70$ system. Computer Science Center, Univ. of Maryland, College Park, Maryland.

TAYloR, R. \& Kennard, O. (1982). J. Am. Chem. Soc. 104, 5063-5070.

Acta Cryst. (1985). C41, 280-282

\title{
Structure of Naproxen, ${ }^{*} \mathrm{C}_{14} \mathrm{H}_{14} \mathrm{O}_{3}$
}

\author{
By K. Ravikumar, $†$ S. S. Rajan $\ddagger$ AND Vasantha PattabH
}

Department of Crystallography and Biophysics, University of Madras, Guindy Campus, Madras-600025, India

\author{
AND E. J. GABE \\ Department of Chemistry, National Research Council of Canada, Ottawa, Canada K1A $0 R 9$
}

(Received 27 December 1983; accepted 17 October 1984)

\begin{abstract}
An effective inhibitor of cyclo-oxygenase. $M_{r}=230 \cdot 25$, monoclinic, $P 2_{1}, a=13 \cdot 3150$ (10), $b$ $=5.7765$ (4), $c=7.8732$ (4) $\AA, \beta=93.88(1)^{\circ}, \quad V=$ $604.2(1) \AA^{3}, Z=2, D_{m}=1.25$ (2) (flotation), $D_{x}=$ $1.265 \mathrm{Mg} \mathrm{m}^{-3}, \lambda\left(\mathrm{Mo} K \alpha_{1}\right)=0.70926 \AA, \mu($ Mo $K \alpha)=$ $0.095 \mathrm{~mm}^{-1}, \quad F(000)=244, \quad T=296 \mathrm{~K}$, final $R(F)$ $=0.061$ for 1037 observed reflections. The rotation of the carboxyl group with respect to the benezene ring, which seems to be connected with anti-inflammatory potential, is similar to the other two substituted propionic acids already reported. The benzene rings in the naphthyl group are inclined at an angle of $5.2(2)^{\circ}$.
\end{abstract}

Introduction. The title compound, an effective inhibitor of the cyclo-oxygenase responsible for biosynthesis of prostaglandins, was obtained from $\mathrm{Dr}$ Natarajan, Institute of Basic Medical Sciences, Madras. It exhibits anti-inflammatory, analgesic and antipyretic activity in man (Goodman \& Gilman, 1980). The analysis of its structure was undertaken to help to establish the structure-activity relationship in propionic acid derivatives.

* IUPAC name: ( \pm )-2-(6-methoxy-2-naphthyl)propionic acid.

+ Contribution No. 654 from the Department of Crystallography and Biophysics, University of Madras, Madras-600 025, India.

$\ddagger$ To whom correspondence should be addressed.

$\S$ NRC No. 24032.

$0108-2701 / 85 / 020280-03 \$ 01.50$
Experimental. Single crystals were grown by slow evaporation of a saturated solution in benzene at room temperature. Crystal $0.3 \times 0.3 \times 0.3 \mathrm{~mm}$, mounted parallel to its long axis $(b)$ and aligned to place this along the instrument $\varphi$ axis. Picker PDP8E four-circle diffractometer at the National Research Council, Canada. Graphite-monochromatized Mo $K \alpha$ radiation, $\theta / 2 \theta$ scan technique, line profile analysis (Grant \& Gabe, 1978), $2 \theta \leq 60^{\circ}, 1167$ unique reflections with $-15<h<15,0<k<6,0<l<9 ; 1037$ with $I_{\text {net }}>$ $2 \cdot 5 \sigma\left(I_{\text {net }}\right)$ based on counting statistics. Intensities for measured direct-beam polarization (Le Page, Gabe \& Calvert, 1979) and Lorentz effects. Absorption corrections not applied. Unit-cell parameters from the least-squares refinement of the setting angles of 40 reflections with $2 \theta>40^{\circ}$. Structure solved by direct methods with MULTAN (Germain, Main \& Woolfson, 1971). $E$ values larger than 1.5 used for phase generation; solution from the set having the highest combined figure of merit. The $E$ map revealed the 17 non-hydrogen atoms. All $14 \mathrm{H}$ atoms located from the $\Delta F$ map. Full-matrix refinement was completed with anisotropic temperature factors for non-hydrogen atoms and isotropic for $\mathrm{H}$ atoms. Final $R(F)=0.061$ and $R_{w}(F)=0.053$ for observed reflections; $R=0.074$ and $R_{w}=0.053$ for all reflections; $w=1 / \sigma^{2}\left(F_{o}\right)$ based on counting statistics; goodness of fit 2.6 . The final difference synthesis showed no peaks above $0.3 \mathrm{e} \AA^{-3}$;

(c) 1985 International Union of Crystallography 